Research Article

\title{
Surface Layer Turbulent Characteristics over the Complex Terrain of the Loess Plateau Semiarid Region
}

\author{
Zhida Zhang $\mathbb{D}^{1}{ }^{1}$ Jiening Liang $\mathbb{D},{ }^{1}$ Min Zhang, ${ }^{1}$ Qi Guo $\mathbb{D}^{1},{ }^{1}$ and Lei Zhang ${ }^{1,2}$ \\ ${ }^{1}$ Key Laboratory for Semi-Arid Climate Change of the Ministry of Education, College of Atmospheric Sciences, \\ Lanzhou University, Lanzhou 730000, China \\ ${ }^{2}$ Collaborative Innovation Center for Western Ecological Safety, Lanzhou University, Lanzhou 730000, China \\ Correspondence should be addressed to Jiening Liang; liangjn@lzu.edu.cn
}

Received 18 December 2020; Revised 6 May 2021; Accepted 3 June 2021; Published 12 June 2021

Academic Editor: Theodore Karacostas

Copyright (c) 2021 Zhida Zhang et al. This is an open access article distributed under the Creative Commons Attribution License, which permits unrestricted use, distribution, and reproduction in any medium, provided the original work is properly cited.

Surface layer turbulence has an important influence on land-air interactions and pollutant dispersion, and studying the characteristics of surface layer turbulence in complex terrain can contribute to understanding land-air interactions, improving model surface layer parameterization, and enhancing pollution prediction capabilities. The surface layer turbulence observations from the Semi-Arid Climate and Environment Observatory (SACOL) of Lanzhou University in 2008 were processed in this study. High-quality turbulence parameters were calculated, the statistical and transfer characteristics of turbulence were analyzed, and the formation of turbulence was assessed in terms of dynamics and thermodynamics. The atmospheric stability in the semiarid region of the Loess Plateau is basically dominated by neutral/near-neutral and weakly unstable/weakly stable conditions; this pattern is significantly different from the preponderance of unstable and stable layers at other sites. The turbulence intensity differs significantly in both the horizontal and vertical directions and basically shows the relationship $I_{u} \approx I_{v}>I_{w}$. The mean values of $I_{u}$ and $I_{v}$ are 0.42 and 0.40 , respectively, and the mean value of $I_{w}$ is 0.14 , which is different from the general pattern of $I_{u}>I_{v}>I_{w}$, indicating that the turbulence intensity at SACOL is characterized by a large lateral wind contribution. The dimensionless standard deviations of the nonneutral wind velocity components satisfy the " $1 / 3 \mathrm{rd} \mathrm{law}$," and the dimensionless standard deviations of $u, v$, and $w$ components are 3.35, 2.98, and 1.26, respectively, in the semiarid Loess Plateau. These values are larger than those over flat terrain. The contribution of the shear term to the formation of turbulence is greater than that of the buoyancy term, and the mean annual values of the shear term and the buoyancy in the kinetic energy budget equation in SACOL are $47.94 \times 10^{-4} \mathrm{~m}^{2} \cdot \mathrm{s}^{-3}$ and $11.32 \times 10^{-4} \mathrm{~m}^{2} \cdot \mathrm{s}^{-3}$, respectively. The annual mean values of the momentum transfer coefficient $C_{D}$ and the heat transfer coefficient $C_{H}$ under near-neutral conditions are $8.54 \times 10^{-3}$ and $2.52 \times 10^{-3}$, respectively.

\section{Introduction}

The study of the atmospheric boundary layer is a major focus in Earth system science, as the exchange of materials and energy within the layer has a significant impact on weather and climate processes [1]. The boundary layer is also a major conduit for ecosystem feedback to the atmosphere and is the region where many pollutants accumulate, including aerosols, with aerosol distribution and pollutant dispersion being directly influenced by turbulent activity within the boundary layer [2]. Sudden meteorological hazards such as dense fog and dust are also closely related to boundary layer processes. Due to surface forcing processes, such as frictional dragging, heat transfer, and evapotranspiration, turbulence is the dominant form of movement in the surface layer atmosphere and serves as a bridge and channel for the exchange of energy and materials between the surface and the atmosphere, such as heat and moisture. Therefore, an in-depth study of the turbulence characteristics in the atmospheric boundary layer, especially in the surface layer, is important for understanding land-air interactions, improving the model's performance over complex terrain, improving air pollution prediction, and the efficient use of wind energy.

At present, a great deal of research has been carried out on the near-surface formation problem over horizontal uniform flat underlying surfaces [3-7]. The Monin- 
Obukhov similarity theory (MOST) has been validated and largely agreed upon in unstable conditions and flat terrain areas. However, the understanding of complex surface turbulence is still poor, and the need to characterize surface layer turbulence over complex terrain is becoming more urgent with the development of higher-resolution weather models and the increased accuracy of simulation results for boundary layer parameterization and turbulence closure schemes. Rotach et al. [8] and Fernando et al. [9] studied land-atmosphere interactions in complex terrain and pointed out that secondary circulation, such as valley winds, causes spatial inhomogeneity in turbulence. Hooke et al. [10] verified the applicability of MOST to complex terrain, noting that it is only applicable to horizontal wind velocities in a specific stability interval ( -0.5 to 0$)$. Moraes et al. [11] stated that the normalized standard deviation of horizontal wind velocity increases with increasing stability, mainly due to the fact that $u_{*}$ decreases rapidly with increasing stability. For complex terrain, Martins et al. [12] observed the standard deviations of velocities and temperature fluctuations at the edge of a sharp cliff, suggesting that complex topography causes quasimesoscale motions, such as gravity waves and local circulation, which change the structure of the turbulence. de Franceschi et al. [13] fitted the empirical coefficient with along-valley and cross-valley winds for $u, v, w$, and $\theta$, respectively, and confirmed the validity of MOST over both stability ranges and for all wind velocity components. Babic et al. [14] used the stationary datasets in Owens valley, in which nonstationarity in turbulence was removed to investigate how the stationarity criterion affects the fluxvariance similarity functions and systematic differences from previously near-neutral values of the parameters in the flux-variance similarity functions over flat terrain were found, indicating a larger anisotropy of the flow over complex than over flat terrain. Nadeau et al. [15] found for a steep slope that the scaling was successful for the fluxvariance similarity functions, but not for the flux-gradient similarity functions, especially during stable conditions. Disparities such as those presented above call for further measurement campaigns to be conducted over complex terrain, mainly to obtain a more definitive and conclusive range of the applicability of similarity theory. So, study on characteristics of surface layer turbulence in complex terrain as the Loess Plateau, the similarity of variance relationships in typical complex terrain, the thermal and dynamic contributions of turbulent kinetic energy, and transfer characteristics is demanded.

The semiarid zone of the Loess Plateau, as a globally important and unique geographic region, is widely distributed and sensitive to climate change, making it a crucial area in the study of global change [16]. The eddy-correlation system of the Semi-Arid Climate and Environment Observatory of Lanzhou University (SACOL) was calibrated in 2008 with good continuity and quality of data. A series of previous pieces of literature have analyzed the turbulence and land-atmosphere interaction at SACOL, with this data in 2008, so the data quality is recognized as credible. For instance, Guanghul et al. [17] compared the effects of different processing methods (including the double rotation (DR), planar fit (PF), and fetch planar fit (FPF)) on the results and invested the sensitivity of their results to the processing, suggesting that DR is recommended in the complicated terrain for reducing calculation and improving the data quality. Liang et al. [18-20] explored the effects of low-level jet and mesoscale motion on turbulence, and they also discussed the applicability of similarity theory to SACOL, the energy closure problem, and the influence of topography on turbulence. However, further research is needed on the similarity in the variance characteristics of turbulence influenced by the complex topography of the Loess Plateau region and the dynamics and thermal contributions of turbulence formation. A systematic understanding of surface layer turbulence in the Loess Plateau region will help to provide a parameterization of the surface layer material and energy transfer processes on the complex underlying surface of the Loess Plateau region.

In this paper, the SACOL 2008 surface layer turbulence observation data are quality controlled and revised to calculate the quality of high-quality turbulence parameters (including atmospheric stability, turbulence intensity, dimensionless standard deviation of wind velocity components, turbulence momentum, sensible heat and latent heat flux, buoyancy and shear terms in the turbulence kinetic energy budget equation, and turbulence bulk transfer coefficient). Then, the surface layer turbulence characteristics over complex terrain are analyzed, and the dynamic and thermodynamic function contributions to turbulence formation are evaluated. This provides a database for land-air interaction studies and model parameterization.

\section{Dataset Description and Methodology}

2.1. Observation Sites. The Semi-Arid Climate and Environment Observatory of Lanzhou University (SACOL) is approximately $48 \mathrm{~km}$ southeast of downtown Lanzhou, China, on top of the Cuiying Mountains $\left(35^{\circ} 57^{\prime} 46^{\prime \prime} \mathrm{N}\right.$, $104^{\circ} 8^{\prime} 13^{\prime \prime} \mathrm{E}$ ) at an elevation of 1965.8 meters above sea level. On a large scale, the Cuiying Mountains lie in a southeastnorthwest-oriented basin with an average elevation of approximately $1750 \mathrm{~m}$ at the base of the basin and a relative height of approximately $200 \mathrm{~m}$. On a smaller scale, SACOL is located on a loess mesa surrounded by typical landforms of the Loess Plateau, such as intricate gullies, beams, and ridges [19]. The surface cover is largely native vegetation [16], the flux observation field is largely flat (extending over $1000 \mathrm{~m}$ in the north-south direction and approximately $200 \mathrm{~m}$ in the east-west direction), the average plant height is $0.2 \mathrm{~m}$, the averaged aerodynamic roughness length $z_{0}$ is $0.04 \mathrm{~m}$, and the displacement distance is $d=0.13 \mathrm{~m}$. SACOL is a good representation of the semiarid zone of the Loess Plateau. Since its establishment, SACOL has provided a large amount of valuable information for climate change research in the semiarid zone of the Loess Plateau and has filled the gap in long-term observations of land-air exchange in the semiarid region of the Loess Plateau summer. For more information about SACOL, please refer to Huang et al. [16]. 
2.2. Observation Instruments and Data. SACOL observations are used to analyze the turbulence characteristics of the surface layer typical of the Loess Plateau. The main data consist of continuous observations from the eddy covariance (EC) system in 2008 and contemporaneous data from the Boundary Layer Meteorological Element Gradient Observations tower (BLM tower) and Surface Radiation Observations System. SACOL revised the instrument in 2008, and the data are accurate and reliable. The EC consists of two main components, a three-dimensional ultrasonic anemometer (CSAT3, Campbell), and an open-path infrared gas analyzer (LI7500, LI-COR) with an inductor height of $2.88 \mathrm{~m}$ above ground. The CSAT3 measures wind velocity and ultrasonic virtual temperature in three directions with a sampling frequency of $10 \mathrm{~Hz}$, a horizontal wind velocity resolution of $1.0 \times 10^{-3} \mathrm{~m} \cdot \mathrm{s}^{-1}$ with a measurement accuracy of $\pm 4.0 \mathrm{~cm} \cdot \mathrm{s}^{-1}$, and a vertical wind velocity resolution of $0.5 \times 10^{-3} \mathrm{~m} \cdot \mathrm{s}^{-1}$ with a measurement accuracy of $\pm 2.0 \mathrm{~cm} / \mathrm{s}$. The open-path infrared gas analyzer measures atmospheric $\mathrm{CO}_{2}$ and water vapor concentrations with a sampling frequency of $10 \mathrm{~Hz}$, a resolution of $10^{-3} \mathrm{mg} \cdot \mathrm{m}^{-3}$ and $10^{-4} \mathrm{~g} \cdot \mathrm{m}^{-3}$, and measurement accuracy of $\pm 0.01 \mathrm{mmol} \cdot \mathrm{mol}^{-1}$ and $\pm 0.15 \mathrm{mmol} \cdot \mathrm{mol}^{-1}$, respectively. The BLM tower is $32.5 \mathrm{~m}$ high, with wind speed (014A-L, Met One), temperature, and humidity (HMP45C-L, Vaisala) sensors installed at heights of $1,2,4,8,12,16$, and $32 \mathrm{~m}$, respectively, and a wind direction sensor (034B-L, Met One) at $8 \mathrm{~m}$. Moreover, a CS105 barometric pressure sensor is installed at $1 \mathrm{~m}$ to detect and record atmospheric pressure. The surface radiation observation system is installed at a height of $1.5 \mathrm{~m}$ and consists of a total diurnal radiometer (CM21, Kipp \& Zonen) and a surface radiometer (CG4, Kipp \& Zonen) with observation values for total solar radiation, reflected solar radiation, atmospheric counterradiation, and surface longwave radiation. The main observations, instrument types, and installation locations are listed in Table 1.

To ensure the accuracy and validity of the results, the EC data at $10 \mathrm{~Hz}$ are processed according to the recommendations of the Global Flux Observation Network (FLUXNET) by eliminating the noise signal (diagnostic value diag_csat $\neq 0$ for CSAT3) caused by inherent conditions, such as instrument power failure and malfunction, and environmental factors, such as rain, dust, and flying insects. Then, despiking [22], DR of coordinates [4], humidity correction for ultrasound virtual temperature $[23,24]$, and density correction [25] were performed in an orderly manner. Pulsation, variance, and covariance were calculated on a 30 minute averaging period for the quality-controlled data. It is worth mentioning that Beijing time (BJT) was used for all times; BJT is $8 \mathrm{~h}$ earlier than universal time and $1 \mathrm{~h}$ earlier than the local time of SACOL. The seasons are divided into spring (March-May), summer (June-August), autumn (September-November), and winter (December-February). The hours are divided into 07:30-19:00 for the day and 19: 30-07:00 for the night.

The gradient term $(\partial u / \partial z)$, required to calculate the tangential term in the turbulence kinetic energy budget equation, is calculated from the wind velocity at the heights of the boundary layer gradient towers of $2 \mathrm{~m}$ and $4 \mathrm{~m}$. In addition, a reference height of $4 \mathrm{~m}$ is used to calculate the wind velocity and temperature difference between the reference height and the ground surface when calculating the bulk transfer coefficient.

Surface radiation data are used to calculate surface temperatures:

$$
T_{s}=\left[\frac{\mathrm{ULR}-(1-\varepsilon) \mathrm{DLR}}{\sigma \varepsilon}\right]^{1 / 4} .
$$

ULR is surface upward longwave radiation, DLR is atmospheric downward longwave radiation, $\varepsilon$ is the surfacespecific emissivity $(\varepsilon=0.95)$, and $\sigma$ is the Stefan-Boltzmann constant $\left(\sigma=5.67 \times 10^{-8} \mathrm{~W} \cdot \mathrm{m}^{-2} \cdot \mathrm{K}^{-4}\right)$.

2.3. EC Method. According to the Reynolds decomposition, the physical quantity $s$ can be decomposed in the average duration $t$ (we use 30 minutes here) into the sum of the average quantity $\bar{s}$ and the pulsating quantity, and the turbulent pulsating quantity can be obtained by removing the average quantity from the measured instantaneous value as follows:

$$
s^{\prime}=s-\bar{s} .
$$

The variance $s^{\prime} s^{\prime}$ and the covariance of the vertical wind speed and the physical quantities $w^{\prime} s^{\prime}$ are averaged over the mean duration $t$ to obtain the mean variance $s^{\prime} s^{\prime}$ and the mean covariance $\overline{w^{\prime} s^{\prime}}$; thus, information on turbulence intensity and flux is demonstrated. The momentum flux $\tau$, the sensible heat flux $H s$, and the latent heat flux $\lambda E$ of turbulence in the vertical direction are

$$
\begin{aligned}
\tau & =-\rho_{a} \overline{w^{\prime} u^{\prime}}, \\
\mathrm{Hs} & =\rho_{a} C_{p} \overline{w^{\prime} T^{\prime}}, \\
\lambda E & =\lambda \overline{w^{\prime} \rho_{v}^{\prime}},
\end{aligned}
$$

where $\rho_{a}$ is the air density $\left(\mathrm{kg} \cdot \mathrm{m}^{-3}\right) ; w$ and $u$ are the vertical and horizontal components of the wind velocity $\left(\mathrm{m} \cdot \mathrm{s}^{-1}\right)$, respectively; $\rho_{v}$ is the water vapor density $\left(\mathrm{kg} \cdot \mathrm{kg}^{-1}\right) ; E$ is the water vapor flux $\left(\mathrm{kg} \cdot \mathrm{m}^{-2} \cdot \mathrm{s}^{-1}\right) ; \lambda$ is the latent heat of vapor evaporation $\left(\mathrm{J} \cdot \mathrm{kg}^{-1}\right)$; and $C_{p}$ is the specific heat of air at constant pressure $\left(\mathrm{J} \cdot \mathrm{kg}^{-1} \mathrm{~K}^{-1}\right)$.

\section{Results and Discussion}

3.1. Atmospheric Stability Parameter. According to MOST, the properly scaled dimensionless characteristics of the turbulence at reference height $z_{m}$ are universal functions of a stability parameter, $\zeta=z_{m}-d / L$, where $d$ is the displacement distance. It is generally considered that the displacement distance of the underlying surface under uniform dense vegetation coverage is $d=2 / 3 h, h$ is the mean height of vegetation, and $L$ is the Obukhov length:

$$
L=-\frac{u_{*}^{3}}{\kappa(g / \theta) \overline{w^{\prime} \theta^{\prime}}} .
$$


TABLE 1: Main observation systems, instrument types, and installation heights.

\begin{tabular}{|c|c|c|c|c|}
\hline Observation system & Instrument & Type & Manufacturer & Installation height \\
\hline \multirow{4}{*}{$\begin{array}{l}\text { Boundary layer meteorological } \\
\text { elements }\end{array}$} & Wind velocity sensor & 014A-L & Met One & $1,2,4,8,12,16$, and $32 \mathrm{~m}$ \\
\hline & Wind direction sensor & 034B-L & Met One & $8 \mathrm{~m}$ \\
\hline & Temperature and humidity probe & $\begin{array}{l}\text { HMP45C- } \\
\text { L }\end{array}$ & Vaisala & $1,2,4,8,12,16$, and $32 \mathrm{~m}$ \\
\hline & Barometric pressure sensor & CS105 & Vaisala & $1 \mathrm{~m}$ \\
\hline \multirow[b]{2}{*}{ Eddy covariance system } & \multirow{2}{*}{$\begin{array}{c}\text { 3D sonic anemometer } \\
\text { Opened path infrared } \mathrm{CO}_{2} / \mathrm{H}_{2} \mathrm{O} \\
\text { analyzer }\end{array}$} & CSAT3 & Campbell & $2.88 \mathrm{~m}$ \\
\hline & & LI7500 & LI-COR & $2.88 \mathrm{~m}$ \\
\hline \multirow{2}{*}{ Surface radiation observation system } & Shortwave radiation & CM21 & Kipp \& Zonen & $1.5 \mathrm{~m}$ \\
\hline & Longwave radiation & CG4 & Kipp \& Zonen & $1.5 \mathrm{~m}$ \\
\hline
\end{tabular}
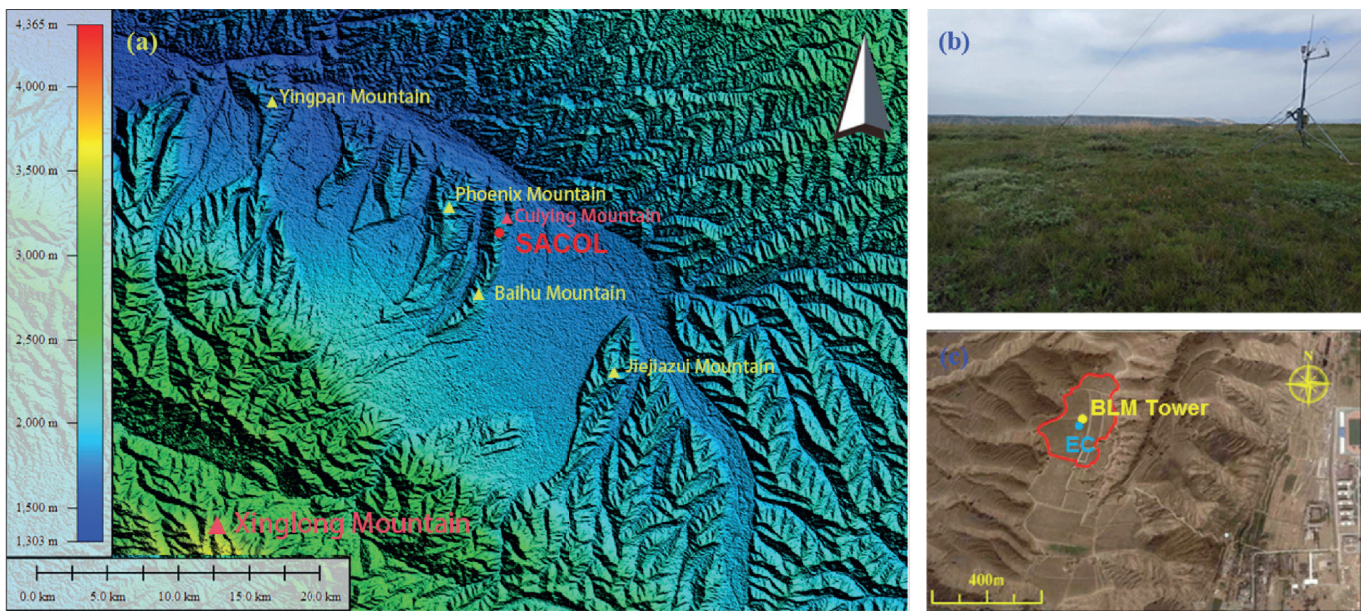

Figure 1: (a) Topographic map of the Semi-Arid Climate and Environment Observatory of Lanzhou University (SACOL), (b) vegetation of the flux observation field in summer, and (c) area surrounding the observation field obtained from Google Earth. The area surrounded by the red line is the observation field, and yellow and blue circles represent the locations of the boundary layer meteorological tower (BLM tower) and the eddy covariance (EC) system. The figure is from Liang et al. [18], and the topographic map in Figure 1(a) is drawn using ASTER GDEM v2 data [21].

In equation (4), $u_{*}=\left[\left(-\overline{u^{\prime} w^{\prime}}\right)^{2}+\left(-\overline{v^{\prime} w^{\prime}}\right)^{2}\right]^{1 / 4}$ is the friction velocity, $\kappa$ is the von Karman constant (whose value interval is usually $0.35 \sim 0.40$, and we adopt 0.40 here), and $g$ is the acceleration due to gravity.

Figure 2 shows the distribution of atmospheric stability for SACOL 2008 throughout the year and shows that the surface layer atmospheric stability is dominated by neutral/ near-neutral and weakly unstable/stable conditions, with few cases of strong stability and strong instability. This differs from the classical stability characteristics over flat terrain [26], which is usually dominated by unstable and stable conditions. This is due to the fact that, under complex topographic conditions, there is strong turbulence-related mixing in the surface layers, which makes it difficult to maintain strong stratification, such as strong stability and strong instability, which has been confirmed by multiple observation experiments $[27,28]$. The daytime stratification is dominated by instability, with a mean value of -0.27 , while the nighttime stratification is dominated by stability, with a mean value of 0.19 . Considering that there are significant seasonal and diurnal variations in atmospheric stability, the daytime and nighttime distributions of stability in different seasons are presented in Table 2. The surface layer stratification was mainly unstable in the daytime and mainly stable at night. The average stability in winter was 0.03 , which was significantly higher than that in other seasons.

3.2. Turbulence Intensity. Turbulence intensity, which is the ratio of the standard deviation of wind velocity to the mean wind velocity, is a commonly used measure of turbulence strength and is an important physical quantity for characterizing atmospheric turbulence motion:

$$
I_{x}=\frac{\sigma_{x}}{U}
$$

where $I_{x}$ is the turbulence intensity in three directions, $x=u, v, w, \sigma_{x}=\sqrt{\overline{x^{\prime 2}}}$ is the standard deviation of the corresponding wind velocity, and $U=\sqrt{u^{2}+v^{2}}$ is the average horizontal wind velocity over average duration $t$.

Figure 3 shows the average diurnal variation in turbulence intensity, wind velocity, and stability throughout the year. The diurnal variation in turbulence intensity is clearly characterized by a single-peak pattern, with 


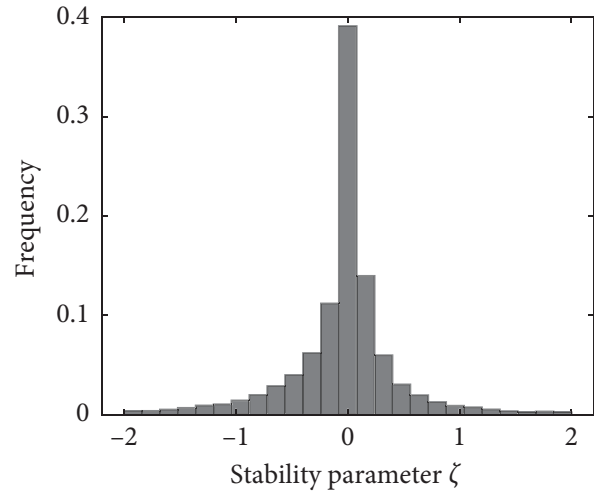

(a)

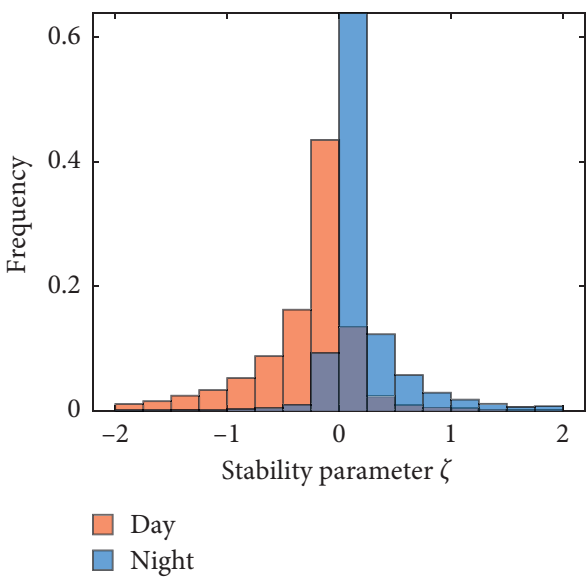

(b)

FIgURE 2: Histograms of the frequency distribution of atmospheric stability throughout the year. All in (a) and day and night in (b).

TABLE 2: Atmospheric stability during different seasons during the day and night.

\begin{tabular}{lcc}
\hline & Day & Night \\
\hline Spring & -0.30 & 0.16 \\
Summer & -0.33 & 0.16 \\
Autumn & -0.28 & 0.21 \\
Winter & -0.19 & 0.24 \\
\hline
\end{tabular}

maximum $I_{u}$ and $I_{v}$ values of 0.68 and 0.66 , respectively, at approximately 14:00. $I_{w}$ also exceeds 0.2 , and the turbulence intensity is smaller at night, with $I_{u}$ and $I_{v}$ values of approximately 0.3 and $I_{w}$ values of approximately 0.1 . The average wind velocity and stability show opposite trends to the intensity of turbulence. At midday, when the average wind velocity is minimal, the atmospheric stratification is predominantly unstable, and turbulence develops most intensively, at night, when the wind velocity is higher, the boundary layer is more clearly stratified, stable stratification predominates, turbulence is inhibited by the stratification, and the turbulence intensity is limited to a low level. The turbulence intensity varies considerably in both horizontal and vertical directions, basically as $I_{u} \approx I_{v}>I_{w}$, which is different from the general characteristic of turbulence intensity over most of the other land surfaces, such as grassland of the central United States [4], which always exhibit the pattern $I_{u}>I_{v}>I_{w}$. The annual averages of $I_{u}, I_{v}$, and $I_{w}$ are 0.42 , 0.40 , and 0.14 , respectively. The complex topographic relief in SACOL results in a local wind field that is subject to a variety of motions, such as secondary circulation, quasisteady motion, and other changes; consequently, the wind direction is complex and variable, with turbulent lateral wind contributing significantly.

Atmospheric stratification is divided into unstable $(\zeta<0)$, stable $(\zeta>0)$, and near-neutral $(-0.1 \leq \zeta \leq 0.1)$ conditions to further investigate the turbulence characteristics under different stratification conditions. Table 3 shows the distribution of turbulence intensity in different seasons and under different stratification conditions. The turbulence intensity shows significant differences between different stability levels within the same season, and $I_{u}, I_{v}$, and $I_{w}$ decrease uniformly with increasing stability. It is worth noting that the season-related differences are far less than the stability-related differences.

3.3. Normalized Standard Deviation of the Velocity Fluctuations. According to the Monin-Obukhov similarity theory (MOST), the dimensionless standard deviation of wind velocity in surface layer turbulence is a universal function of $\zeta[29,30]$, and there is a uniform form between them:

$$
\begin{aligned}
\frac{\sigma_{j}}{u_{*}} & =\phi_{j}(\zeta), \quad(j=u, v, w) \\
& =C_{x 1}\left(1-C_{x 2} \frac{z}{L}\right)^{1 / 3},
\end{aligned}
$$

where $\sigma_{j}$ is the standard deviation of the variable $j, u_{*}$ is the frictional velocity, $\phi_{j}$ is a universal function, and $C_{x 1}$ and $C_{x 2}$ are the empirical coefficients. Under neutral conditions, $\zeta=0$, where turbulence is purely mechanical, the dimensionless standard deviations of the wind velocity components $u, v$, and $w$ will be constants, independent of roughness and height [31]. The similarity of the variance relationship in the form of equation (6) is referred to below as the " $1 / 3$ rd law." The empirical relations (equations (7) and (8)) summarized by Panofskyet al. [32] for flat and homogeneous surfaces are the most widely used but have different statistical results for many different surfaces and 


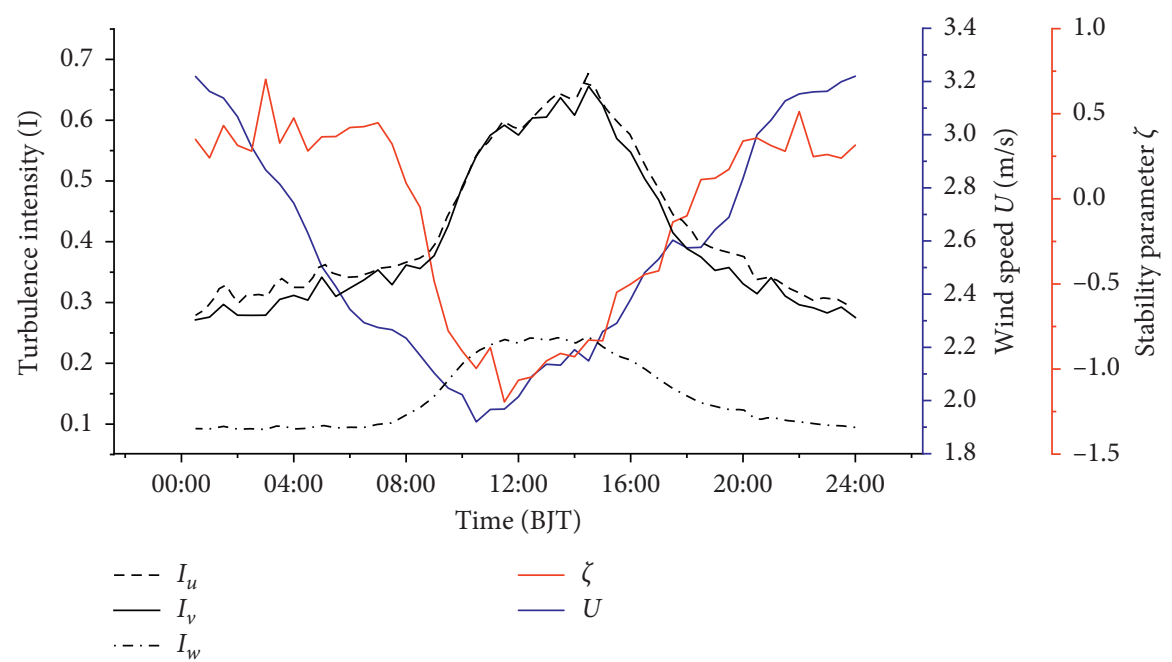

FIgURE 3: Average diurnal variation in annual turbulence intensity with wind velocity and stability.

TABLE 3: Turbulence intensity of $u, v$, and $w$ under different stability conditions and in different seasons.

\begin{tabular}{|c|c|c|c|c|c|}
\hline & Turbulence intensity & Spring & Summer & Autumn & Winter \\
\hline \multirow{3}{*}{ Unstable $(\zeta<0)$} & $I_{u}$ & 0.56 & 0.55 & 0.55 & 0.53 \\
\hline & $I_{v}^{u}$ & 0.54 & 0.53 & 0.54 & 0.51 \\
\hline & $I_{w}$ & 0.20 & 0.20 & 0.21 & 0.19 \\
\hline \multirow{3}{*}{ Near-neutral $(|\zeta| \leq 0.1)$} & $I_{u}$ & 0.36 & 0.35 & 0.33 & 0.39 \\
\hline & $I_{v}$ & 0.33 & 0.31 & 0.30 & 0.36 \\
\hline & $I_{w}$ & 0.13 & 0.13 & 0.12 & 0.12 \\
\hline \multirow{3}{*}{ Stable $(\zeta>0)$} & $I_{u}$ & 0.31 & 0.31 & 0.30 & 0.32 \\
\hline & $I_{v}$ & 0.30 & 0.28 & 0.28 & 0.30 \\
\hline & $I_{w}$ & 0.10 & 0.10 & 0.09 & 0.09 \\
\hline
\end{tabular}

different terrain $[13-15,33,34]$. However, they emphasized the further need for measurements of turbulence quantities at much more typical complex terrain. The empirical relationships in SACOL, which can represent the Loess Plateau, are not clear and need to be investigated.

$$
\begin{aligned}
& \frac{\sigma_{u}}{u_{*}} \simeq \frac{\sigma_{v}}{u_{*}}=\left[12+0.5\left(\frac{z}{-L}\right)\right]^{1 / 3}, \\
& \frac{\sigma_{w}}{u_{*}}=1.25\left(1-3 \frac{z}{L}\right)^{1 / 3} .
\end{aligned}
$$

3.3.1. Near-Neutral Stratification $(|\zeta| \leq 0.1)$. The dimensionless standard deviations of the three-dimensional velocity fluctuations $\sigma_{u} / u_{*}, \sigma_{v} / u_{*}$, and $\sigma_{w} / u_{*}$ in SACOL are $3.35,2.98$, and 1.26 , respectively, which are close to the results for an area of undulating terrain in a Florida state park [35] $(3.20,2.90$, and 1.24) and greater than the average results $(2.39 \pm 0.03,1.92 \pm 0.05$, and $1.25 \pm 0.03)$ for several sites with flat terrain, including Roskilde (Denmark), Ladner (Canada), and Donaldson (Minnesota) [35]. The dimensionless standard deviation of the horizontal wind velocity is larger than that of the vertical wind velocity. $\sigma_{w} / u_{*}$ in complex terrain differs little from that in flat terrain, while $\sigma_{u} / u_{*}$ and $\sigma_{v} / u_{*}$ are significantly larger than those in flat terrain. This is because horizontal fluctuations are mainly generated by relatively large quasihorizontal turbulences, which typically have diameters of several hundred meters or more and are less adaptable to the terrain than vertical pulsations, which are dominated by the contribution of relatively small turbulences [31], so the influence of topography on turbulence is more pronounced in the horizontal direction.

3.3.2. Nonneutral Stratification (Stable $(\zeta>0)$ and Unstable Conditions $(\zeta<0))$. Although the $1 / 3$ rd law of dimensionless standard deviation of wind velocity under unstable conditions has been widely demonstrated, it is debatable whether the dimensionless standard deviation of wind velocity under stable stratification is satisfied. Figure 4 shows the relationship between the dimensionless standard deviations of the SACOL wind velocity components $u, v$, and $w$ with respect to the stability parameter $\zeta$. The dimensionless standard deviation of the wind velocity in all three directions satisfies the $1 / 3$ rd law reasonably well when unstable, in the form of formulas (9)-(11). The standard deviation of the dimensionless wind velocity increasing with $\zeta$ in the stable boundary layer has been observed at many sites and has been the focus of discussion in this field of study. On the one 
hand, under stable conditions, $\sigma_{j} / u_{*}, \quad(j=u, v, w)$ and $u_{*}$ are both small, so there is large uncertainty in the ratio between them. Additionally, there is also a serious uncertainty in $u_{*}$ itself, and a tendency to overestimate $\sigma_{j} / u_{*}$ due to underestimation of $u_{*}$ can easily be observed [31]. In recent years, an increasing number of studies have found that, in a stable boundary layer, turbulent motion is influenced by a variety of unsteady motions that are significantly intermittent, leading to an enhancement in turbulent motion over short periods of time, resulting in an increase in $\sigma_{j} / u_{*}[20,36]$. Furthermore, considering that $u_{*}$ occurs in both $\zeta$ and $\sigma_{j} / u_{*}, \zeta$ is proportional to $1 / u_{*}^{3}$, and $\sigma_{j} / u_{*}$ is proportional to $1 / u_{*}$, resulting in a spurious $1 / 3 \mathrm{rd}$ order relationship, which is generally called the self-correlation relationship [37]. It has been shown that this self-correlation is more pronounced in the strong stable case (such as $\zeta>1 \sim 2)$ and when the data are discrete $[38,39]$.

$$
\begin{aligned}
& \frac{\sigma_{u}}{u_{*}}=\phi_{u}(\zeta)= \begin{cases}2.96(1+10.74 \zeta)^{1 / 3}, & \zeta>0, \\
2.92(1-3.10 \zeta)^{1 / 3}, & \zeta<0,\end{cases} \\
& \frac{\sigma_{v}}{u_{*}}=\phi_{v}(\zeta)= \begin{cases}2.67(1+10.34 \zeta)^{1 / 3}, & \zeta>0, \\
2.67(1-2.99 \zeta)^{1 / 3}, & \zeta<0,\end{cases} \\
& \frac{\sigma_{w}}{u_{*}}=\phi_{w}(\zeta)= \begin{cases}1.22(1+2.15 \zeta)^{1 / 3}, & \zeta>0, \\
1.22(1-1.33 \zeta)^{1 / 3}, & \zeta<0 .\end{cases}
\end{aligned}
$$

3.4. Turbulent Momentum Flux and Heat Flux. The transfer of momentum and heat between the Earth's surface and the atmosphere is a driver of climate from local to global levels and has an important influence on climate change [40]. The semiarid zone of the Loess Plateau has a unique terrain and vegetation type; in this case, a correct understanding of the characteristics of turbulent fluxes, such as momentum and heat, is useful for understanding the earth-air interaction processes in this region.

Figure 5 displays the diurnal variation in the SACOL turbulent momentum. The momentum flux rises gradually during the day to above $0.08 \mathrm{~kg} \cdot \mathrm{m}^{-1} \cdot \mathrm{s}^{-2}$ in the afternoon and decreases at night to a minimum of $0.03 \mathrm{~kg} \cdot \mathrm{m}^{-1} \cdot \mathrm{s}^{-2}$ at approximately 6:00 p.m. Depending on the season, the momentum flux is more similar in spring and summer than in autumn and winter due to seasonal differences in the stability of the surface layer (Table 2). Due to surface-cooling effects, the nighttime stratification is usually stable, which has a restraining effect on turbulence generation, the momentum transfer is low, during the daytime, and heat bubbles caused by heterogeneous surface heating destabilize the atmosphere and promote turbulence formation, resulting in a larger momentum flux.

The heat fluxes show a single-peak diurnal variation pattern in Figure 6, with the sensible and latent heat flux peaking at $148 \mathrm{~W} \cdot \mathrm{m}^{-2}$ and $76 \mathrm{~W} \cdot \mathrm{m}^{-2}$ at approximately $14: 00$ during the day. The latent heat fluxes are almost always positive, and the sensible heat fluxes are positive during the day and negative at night because the surface is exposed to solar radiation during the day; the ground temperature rises and transfers heat to the atmosphere, while at night, the ground temperature is lower than the air temperature due to ground cooling, resulting in downward heat transfer. The peak heat fluxes in the different seasons show that the heat fluxes are higher in spring and summer than in autumn and winter, with diurnal maximum sensible heat fluxes of approximately $200 \mathrm{~W} \cdot \mathrm{m}^{-2}$ at midday in spring and summer and only approximately $100 \mathrm{~W} \cdot \mathrm{m}^{-2}$ in autumn and winter. The latent heat flux in winter is much lower than the sensible heat flux, which is related to the lower atmospheric water vapor in winter.

3.5. Diurnal Variation in the Turbulent Kinetic Energy Budget Term. Moeng and Wyngaard [41] pointed out that the energy needed to sustain turbulence development comes mainly from the shear and buoyancy terms of the turbulence kinetic energy equation (TKE). To simplify the calculations, the coordinate system direction $\bar{u}$ is taken to be in the same direction as the mean wind direction, the turbulence is assumed to be uniform, and subsidence is ignored. The following equation for the kinetic energy of turbulence is obtained:

$$
\frac{\partial \bar{e}}{\partial t}=\frac{g}{T} \overline{w^{\prime} T^{\prime}}-\overline{u^{\prime} w^{\prime}} \frac{\partial \bar{u}}{\partial z}-\frac{\partial \overline{w^{\prime} e^{\prime}}}{\partial z}-\frac{1}{\bar{\rho}} \frac{\partial\left(\overline{\omega^{\prime} p^{\prime}}\right)}{\partial z}-\varepsilon .
$$

The left-hand side of equation (12) represents the local variation in the turbulent kinetic energy $(\partial \bar{e} / \partial t)$, the first term on the right-hand side is the buoyancy term $\left(g / T \overline{w^{\prime} T^{\prime}}\right)$, and the second term is the shear generation term (the shear term is simplified as $-\overline{u^{\prime} w^{\prime}}(\partial \bar{u} / \partial z)$ when the $\bar{u}$ direction of the coordinate system coincides with the mean wind direction). $\partial \bar{u} / \partial z$ is obtained from the wind velocity data of the boundary layer gradient towers at $2 \mathrm{~m}$ and $4 \mathrm{~m}$, and $\overline{w^{\prime} T^{\prime}}$ and $\overline{u^{\prime} w^{\prime}}$ are calculated using the EC system to reach the buoyancy term and the shear term of the turbulence kinetic energy budget equation.

Figure 7 shows the diurnal variation in the turbulent kinetic energy budget. The buoyancy term is mainly influenced by thermal stratification, with a maximum positive value at noon and a smaller negative value at night, which is basically the same as the diurnal variation in the heat flux. The shear term is mainly produced by wind velocity and surface friction, with a minimum value at noon and a maximum value at night, which is close to the diurnal variation in wind velocity but lags behind the diurnal variation in wind velocity by approximately 4 hours.

Table 4 gives the shear and buoyancy terms for turbulence in different seasons. The buoyancy term is larger in spring and summer and smaller in autumn and winter, and the shear term is also significantly smaller in winter than in other seasons. The shear term is also significantly smaller in winter than in other seasons, which is consistent with the seasonal variation in the stability condition. The annual mean of the shear term is greater than that of the buoyancy term, which is $47.94 \times 10^{-4} \mathrm{~m}^{2} \cdot \mathrm{s}^{-3}$ and $11.31 \times \mathrm{m}^{2} \cdot \mathrm{s}^{-3}$, respectively. Under the influence of complex surface friction, 


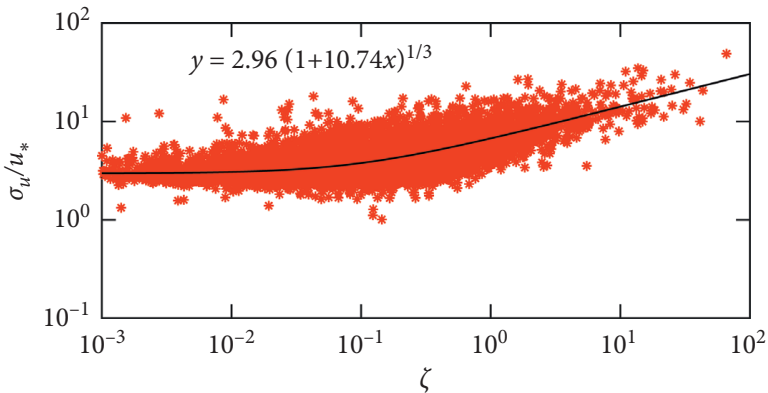

(a)

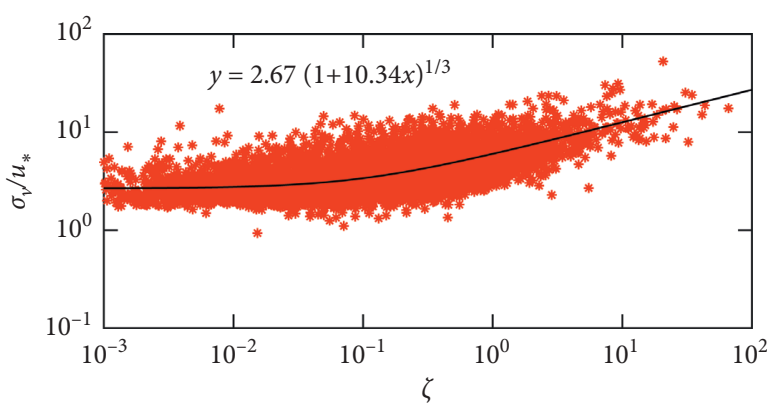

(c)

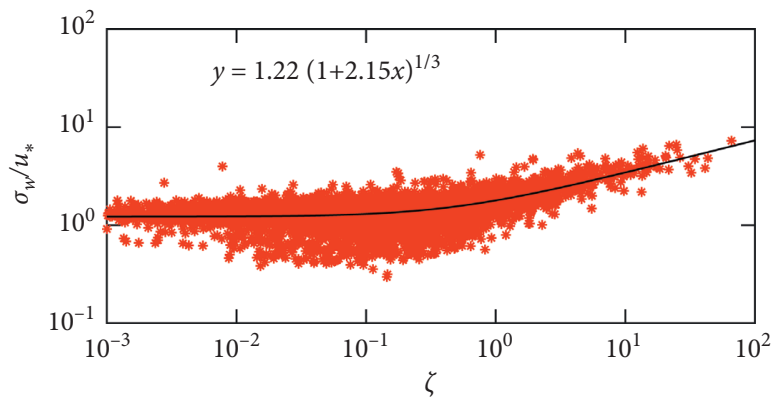

(e)

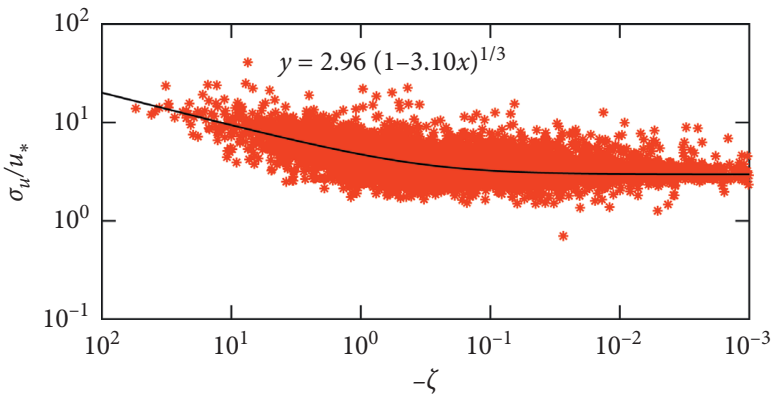

(b)

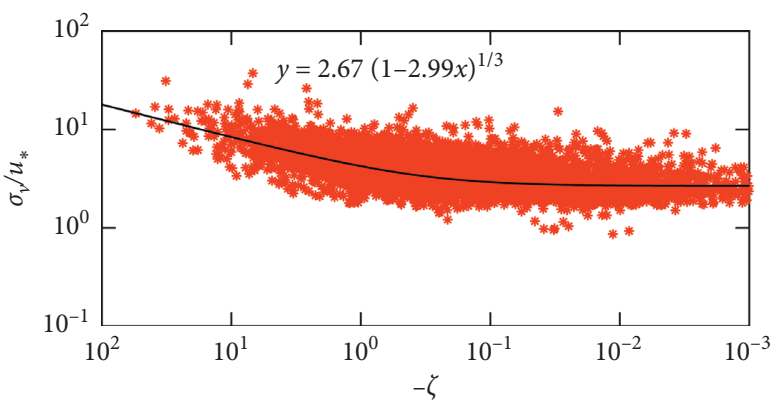

(d)

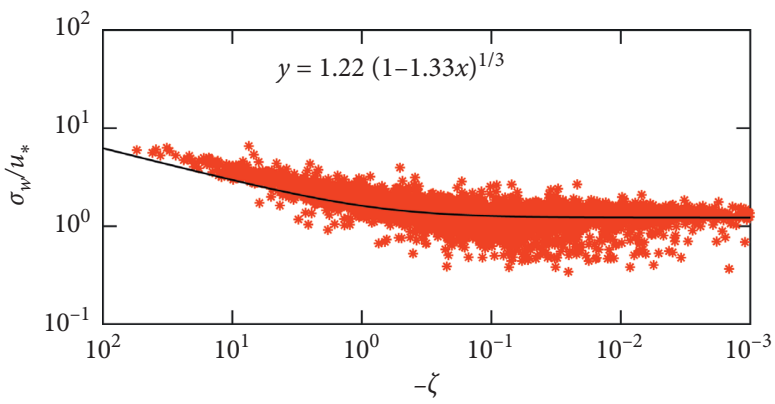

(f)

Figure 4: Relationship between the dimensionless standard deviation of the wind velocity $u$, $v$, and $w$ components and stability. (a, c, e) for the stable case and $(b, d, f)$ for the unstable case.

the contribution of the shear term to turbulence formation in the semiarid region of the Loess Plateau is greater than that of the buoyancy term.

3.6. Bulk Transfer Coefficient of Turbulence. The bulk transfer coefficient is an important parameter for describing the transfer of turbulence at the surface; however, the few studies of bulk transfer coefficients conducted on the land surface mainly focus on uniform underlying surfaces, and the understanding of bulk transfer coefficients on complex terrain is still inadequate, which makes it very difficult to parameterize the boundary layer in atmospheric models. The bulk transfer coefficients of turbulence in complex underlying surfaces in semiarid regions are of great importance for improving the prediction of numerical models and estimating momentum and heat fluxes. In circulation models, momentum transfer and heat transfer coefficients $\left(C_{D}\right.$ and $\left.C_{H}\right)$ are often simply considered constant coefficients $\left(C_{D}\right.$ is approximately $2 \times 10^{-3}$ and $C_{H}$ is approximately $1.5 \times 10^{-3}$ ), without considering the fact that differences in different areas and different underlying surfaces significantly affect the accuracy of the simulations.

$$
\begin{aligned}
& C_{D}=\frac{\tau}{\rho_{a} u^{2}}=\frac{\rho_{a} u_{*}^{2}}{\rho_{a} u^{2}}=\frac{u_{*}^{2}}{u^{2}}, \\
& C_{H}=\frac{\mathrm{Hs}}{\rho_{a} C_{p} u\left(T_{s}-T\right)}=\frac{\overline{w^{\prime} T^{\prime}}}{u\left(T_{s}-T\right)} .
\end{aligned}
$$

Equations (13) and (14) are simplified definitions of the momentum and heat bulk transfer coefficient of turbulence. $T_{s}$ is the surface temperature, $u$ and $T$ are the average wind velocity and temperature at reference height (here, we select $4 \mathrm{~m}$ above ground as the reference height), respectively, and the covariances $\overline{w^{\prime} u^{\prime}}$ and $\overline{w^{\prime} T^{\prime}}$ are directly evaluated from the sonic anemometer measurements.

Figure 8 shows the diurnal variation in the turbulent bulk transfer coefficients of momentum and heat and their distribution with stability. The turbulent bulk transfer of 


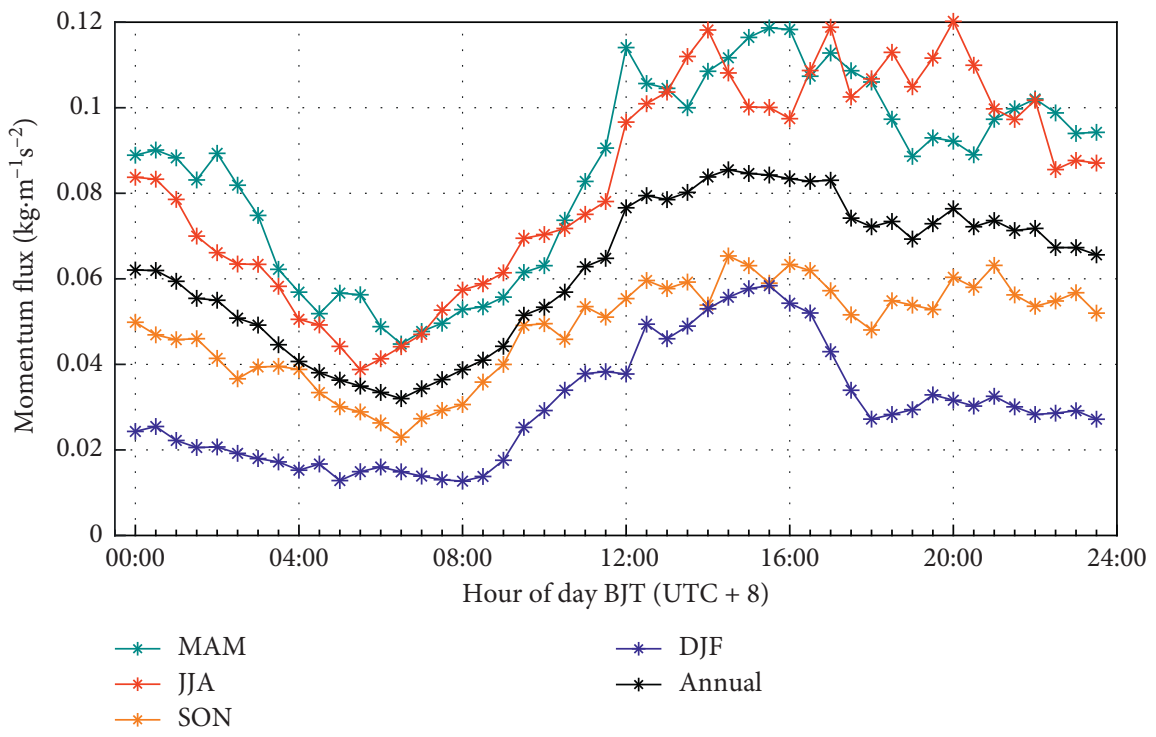

Figure 5: Diurnal variation of turbulent momentum fluxes.

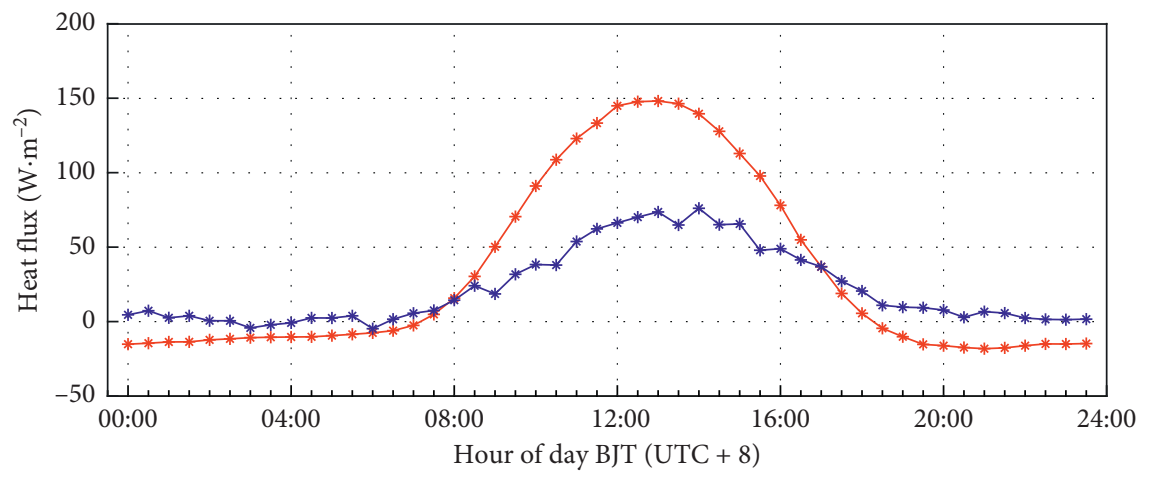

* $\mathrm{Hs}$

$\rightarrow$ LE

(a)

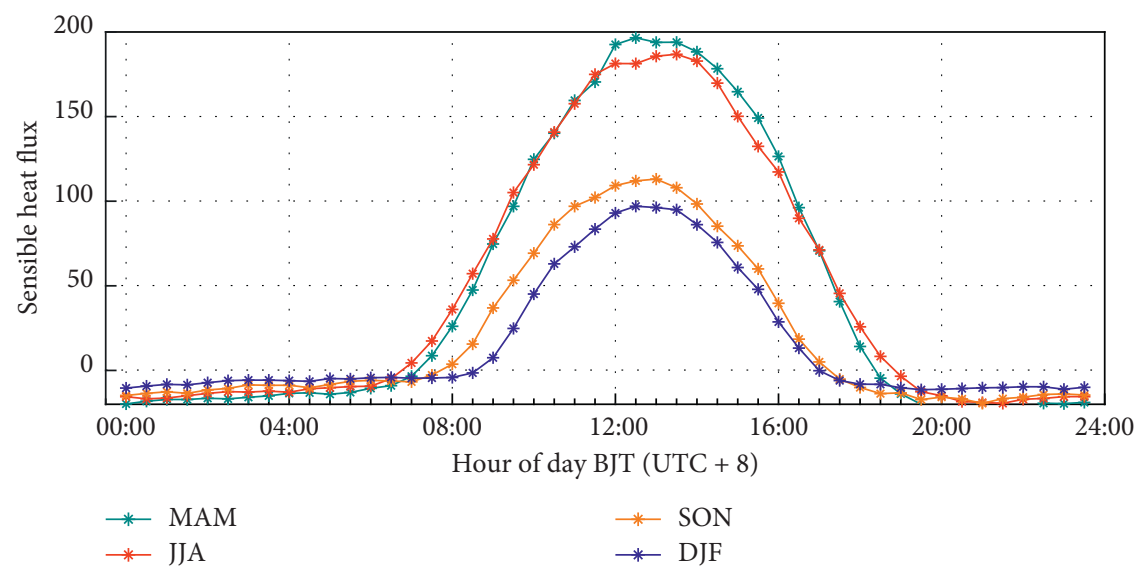

(b)

Figure 6: Continued. 


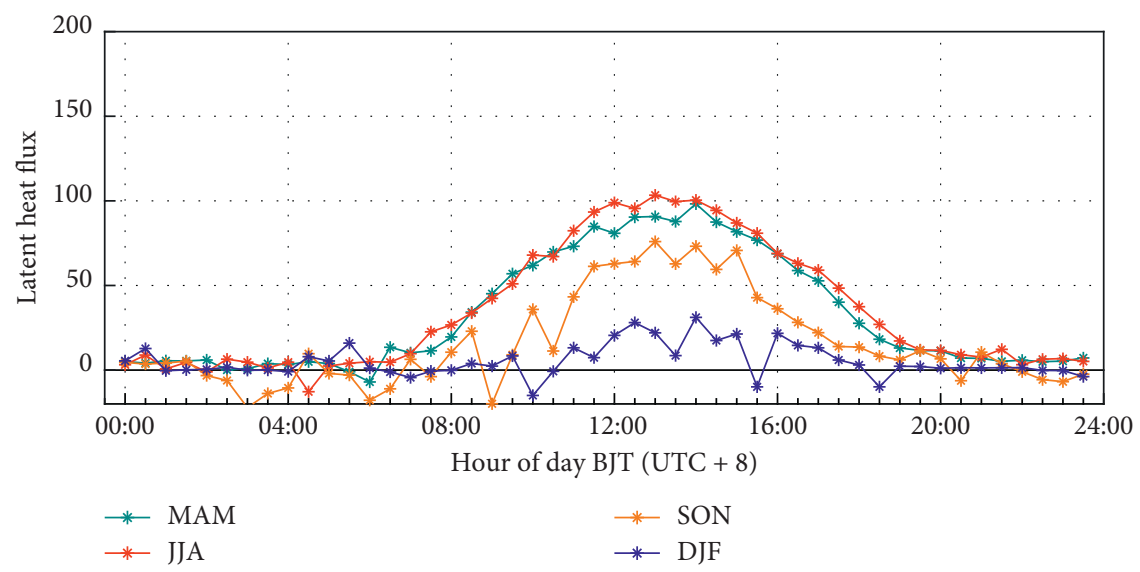

(c)

FIGURE 6: Diurnal variation of sensible and latent heat fluxes. Diurnal variation of sensible heat and latent heat fluxes in (a) and sensible heat flux and latent heat flux in different seasons in (b) and (c), respectively.

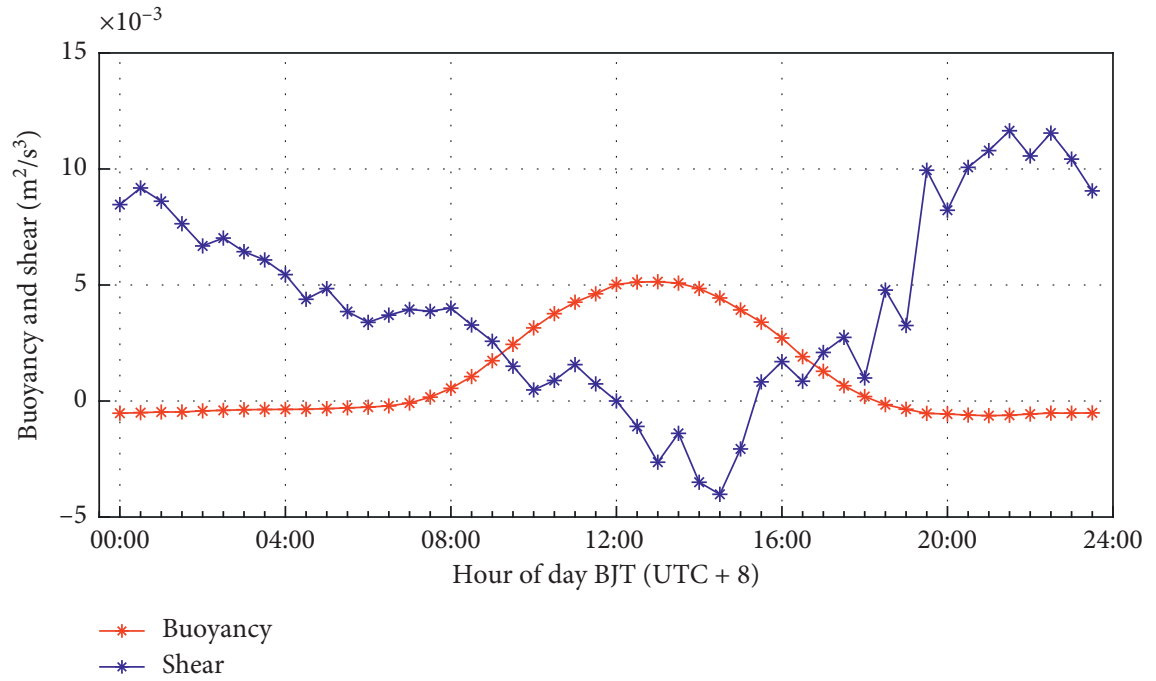

FIgURE 7: Diurnal variation in the annual averaged turbulence kinetic energy budget.

TAвLE 4: Turbulent kinetic energy budget for different seasons and stability conditions.

\begin{tabular}{|c|c|c|c|c|c|c|c|}
\hline Variable & Expression & Stability & Spring & Summer & Autumn & Winter & Mean \\
\hline \multirow{3}{*}{ Buoyancy term } & & Unstable & 39.26 & 37.59 & 22.23 & 16.66 & \multirow{3}{*}{11.31} \\
\hline & $g / T \overline{w^{\prime} T^{\prime}}$ & Near-neutral & 2.95 & 4.47 & -1.02 & 0.50 & \\
\hline & & Stable & -6.43 & -5.24 & -4.71 & -3.36 & \\
\hline \multirow{3}{*}{ Shear term } & & Unstable & -3.33 & 15.37 & 21.70 & -2.44 & \multirow{3}{*}{47.94} \\
\hline & $-\overline{u^{\prime} w^{\prime}} \partial \bar{u} / \partial z$ & Near-neutral & 113.52 & 140.87 & 125.81 & 18.07 & \\
\hline & & Stable & 113.15 & 128.73 & 81.81 & 16.40 & \\
\hline
\end{tabular}

momentum and heat is highest at noon and smaller at night; as the stability increases, both $C_{D}$ and $C_{H}$ show a decreasing trend, and the bulk transfer coefficient of heat changes more markedly. Moreover, in all cases, the bulk transfer coefficient of momentum is larger than that of heat. Table 5 gives the total momentum and heat transfer coefficients for different stability conditions and different seasons. The annual average values of $C_{D}$ and $C_{H}$ for near-neutral conditions are 


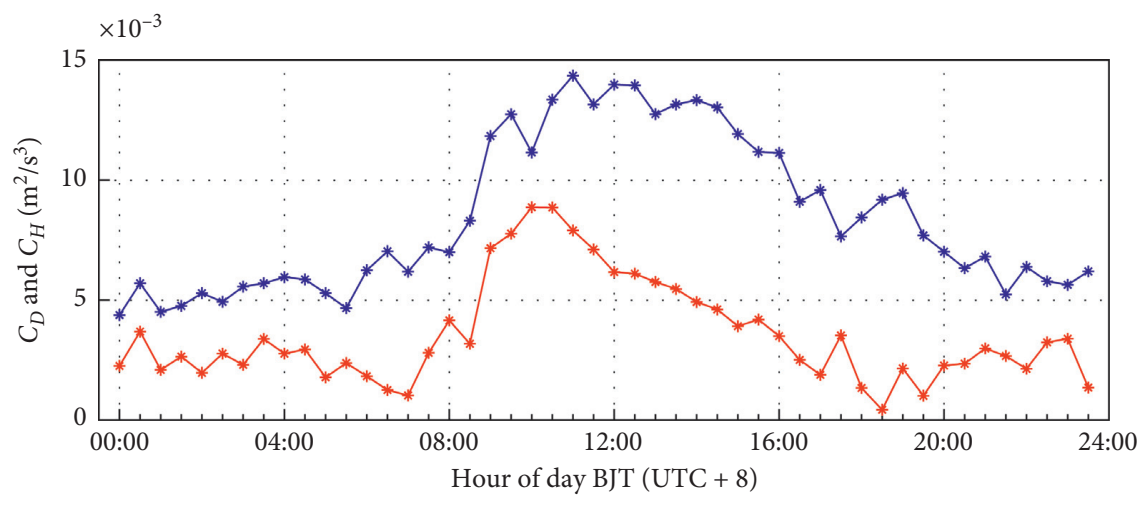

$$
\begin{array}{ll}
* & C_{D} \\
* & C_{H}
\end{array}
$$

(a)

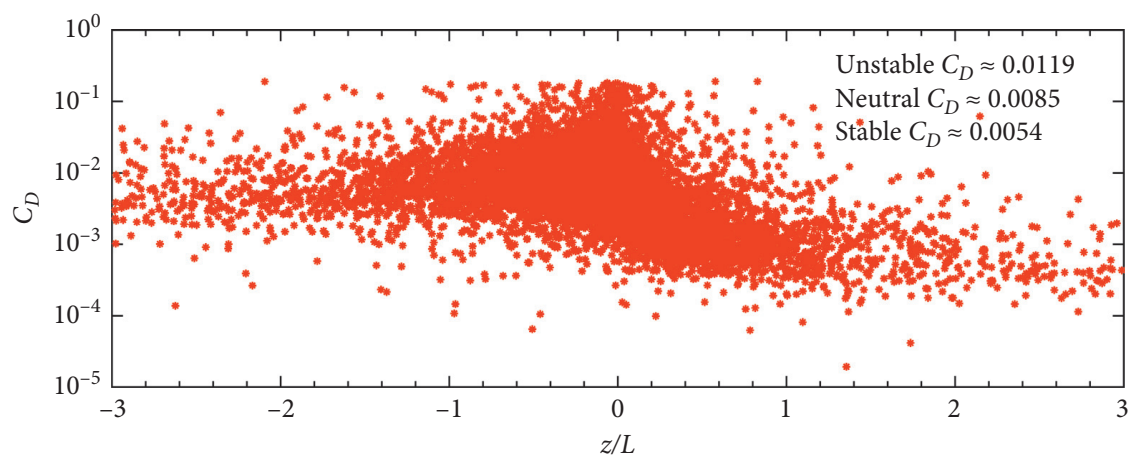

(b)

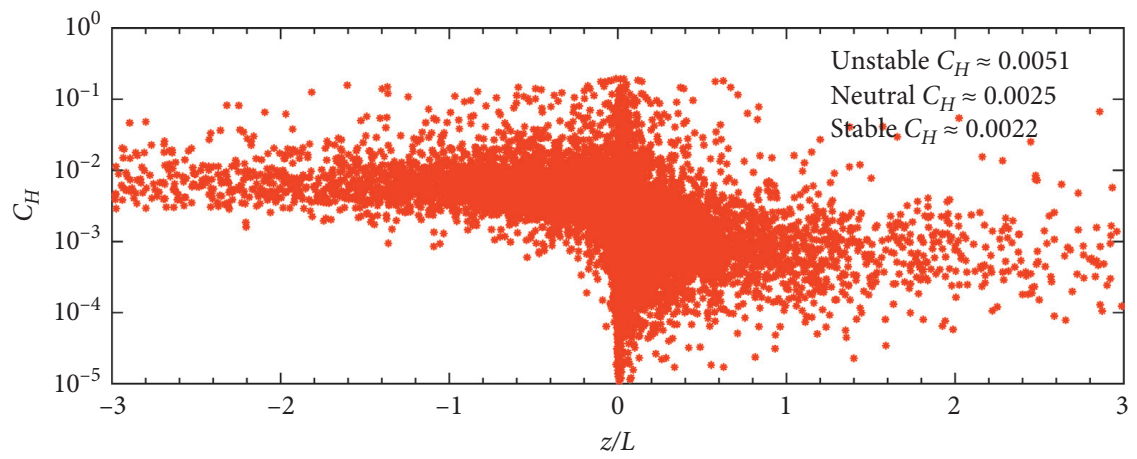

(c)

Figure 8: Diurnal variation of the bulk transfer coefficient and its distribution with stability. (a) The diurnal variation of the bulk transfer coefficient. (b, c) The distribution of the momentum and heat bulk transfer coefficient with stability, respectively.

TABLe 5: Turbulent bulk transfer coefficients under different stability conditions and in different seasons $\left(\times 10^{-3}\right)$.

\begin{tabular}{cccccc}
\hline & Stability & Spring & Summer & Autumn & Winter \\
\hline \multirow{2}{*}{$C_{D}$} & Unstable & 11.73 & 13.82 & 15.89 & 12.39 \\
& Near-neutral & 8.54 & 10.85 & 9.16 & 10.10 \\
& Stable & 6.00 & 8.12 & 5.00 & 7.70 \\
$C_{H}$ & Unstable & 3.63 & 5.89 & 3.60 & 4.38 \\
& Near-neutral & 2.71 & 3.90 & 3.00 & 1.47 \\
\hline
\end{tabular}


$8.54 \times 10^{-3}$ and $2.52 \times 10^{-3}$, which are not listed in Table 5, respectively. The values of $C_{D}$ and $C_{H}$ are much larger than those typically used in models, which should be attributed to the complex terrain in the Loess Plateau. Owing to the same small values used in numerical models in complex terrain as in flat areas, the heat and momentum transport in the complex terrain would be underestimated.

\section{Conclusions}

The EC and boundary layer gradient observatory tower data from the Semi-Arid Climate and Environment Observatory of Lanzhou University (SACOL) were processed with the EC method for quality control and data processing to obtain the statistical parameters of the surface layer turbulence in order to analyze the turbulence characteristics of the complex terrain in the semiarid zone of the Loess Plateau. The formation of turbulence in terms of dynamics and thermal conditions is discussed in this study. The main results are summarized as follows.

The frictional action of the complex surface increases turbulent mixing in the surface layer and weakens stratification, resulting in predominantly neutral/near-neutral and weakly unstable/weakly stable conditions in the semiarid zone of the Loess Plateau. The daytime stratification is predominantly unstable, with a mean value of -0.27 , while the nighttime stratification is predominantly stable, with a mean value of 0.19 . Stability and turbulence intensity show opposite diurnal variations, reaching a minimum and maximum, respectively, at noon, with turbulence intensity decreasing significantly with increasing stability. The turbulence intensity is shown by $I_{u} \approx I_{v}>I_{w}$, which is different from the general pattern of $I_{u}>I_{v}>I_{w}$. The average values of $I_{u}$ and $I_{v}$ are 0.42 and 0.40 , respectively, and the average value of $I_{w}$ is 0.14 , indicating that lateral wind makes a large contribution to turbulence.

The dimensionless standard deviations of $u, v$, and $w$ components of the wind velocity under nonneutral stratification satisfy the 1/3 law relatively well. The dimensionless standard deviations of the wind velocity are significantly larger in the horizontal direction than in the vertical direction, which is related to the larger turbulence scale in the horizontal direction. The dimensionless standard deviations of the three-dimensional wind velocity $\sigma_{u} / u_{*}, \sigma_{v} / u_{*}$, and $\sigma_{w} / u_{*}$ at SACOL under near-neutral stratification are 3.35, 2.98 , and 1.26, respectively. The influence of complex terrain is mainly observed in the horizontal direction, resulting in a significantly higher standard deviation in the horizontal wind velocity over complex terrain than over a flat and uniform surface.

The turbulent kinetic energy budget term and the bulk transfer coefficient of turbulence have been calculated, and their diurnal variation patterns are given. The shear terms greater than the buoyancy term in the semiarid zone of the Loess Plateau are $47.94 \times 10^{-4} \mathrm{~m}^{2} \cdot \mathrm{s}^{-3}$ and $11.31 \times 10^{-4} \mathrm{~m}^{2} \cdot \mathrm{s}^{-3}$, respectively, indicating that wind shear contributes more than buoyancy to turbulence formation in the semiarid zone of the Loess Plateau. The annual mean of the momentum transfer coefficient $C_{D}$ is larger than the heat transfer coefficient $C_{H}$ under near-neutral conditions, which have values of $8.54 \times 10^{-3}$ and $2.52 \times 10^{-3}$, respectively.

\section{Data Availability}

The topographic map in Figure 1(a) is drawn using ASTER GDEM v2 data. ASTER GDEM is a product of METI NASA and is available at http://srtm.csi.cgiar.org. The data used in this study are archived in the sharing data of SACOL (http:// climate.lzu.edu.cn/English/Home_Page.htm) with an application.

\section{Conflicts of Interest}

The authors declare that there are no conflicts of interest regarding the publication of this paper.

\section{Acknowledgments}

The authors are grateful to the Semi-Arid Climate and Environment Observatory of Lanzhou University (SACOL) for the data used herein. This work was jointly funded by the Second Tibetan Plateau Scientific Expedition and Research program (STEP, Grant no. 2019QZKK0602) and the National Natural Science Foundation of China (41605005 and 41521004).

\section{References}

[1] J. R. Garratt, "The atmospheric boundary-layer-review," Earth-Science Reviews, vol. 37, no. 1-2, pp. 89-134, 1994.

[2] J. C. Wyngaard and O. R. Coté, "The budgets of turbulent kinetic energy and temperature variance in the atmospheric surface layer," Journal of the Atmospheric Sciences, vol. 28, no. 2, pp. 190-201, 1971.

[3] J. A. Businger, J. C. Wyngaard, Y. Izumi, and E. F. Bradley, "Flux-profile relationships in the atmospheric surface layer," Journal of the Atmospheric Sciences, vol. 28, no. 2, pp. 181-189, 1971.

[4] J. C. Kaimal and J. J. Finnigan, Atmospheric Boundary Layer Flows: Their Structure and Measurement, Oxford University Press, Oxford, UK, 1994.

[5] L. Mahrt, "Nocturnal boundary-layer regimes," BoundaryLayer Meteorology, vol. 88, no. 2, pp. 255-278, 1998.

[6] F. T. M. Nieuwstadt, "The turbulent structure of the stable, nocturnal boundary layer," Journal of the Atmospheric Sciences, vol. 41, no. 14, pp. 2202-2216, 1984.

[7] Z. Sorbjan, "On similarity in the atmospheric boundary layer," Boundary-Layer Meteorology, vol. 34, no. 4, pp. 377-397, 1986.

[8] M. W. Rotach, P. Calanca, G. Graziani et al., "Turbulence structure and exchange processes in an alpine valley: the riviera project," Bulletin of the American Meteorological Society, vol. 85, no. 9, pp. 1367-1386, 2004.

[9] H. J. S. Fernando, E. R. Pardyjak, S. Di Sabatino et al., "The MATERHORN: unraveling the intricacies of mountain weather," Bulletin of the American Meteorological Society, vol. 96, no. 11, pp. 1945-1967, 2015.

[10] W. Hooke, F. Hall, and E. Gossard, "Observed generation of an atmospheric gravity wave by shear instability in the mean flow of the planetary boundary layer," Boundary-Layer Meteorology, vol. 5, no. 1-2, pp. 29-41, 1973. 
[11] O. Moraes, O. Acevedo, G. Degrazia, D. Anfossi, R. Dasilva, and V. Anabor, "Surface layer turbulence parameters over a complex terrain," Atmospheric Environment, vol. 39, no. 17, pp. 3103-3112, 2005.

[12] C. A. Martins, O. L. L. Moraes, O. C. Acevedo, and G. A. Degrazia, "Turbulence intensity parameters over a very complex terrain," Boundary-Layer Meteorology, vol. 133, no. 1, pp. 35-45, 2009.

[13] M. de Franceschi, D. Zardi, M. Tagliazucca, and F. Tampieri, "Analysis of second-order moments in surface layer turbulence in an alpine valley," Quarterly Journal of the Royal Meteorological Society, vol. 135, no. 644, pp. 1750-1765, 2009.

[14] N. Babic, Z. Vecenaj, and S. F. J. De Wekker, "Flux-variance similarity in complex terrain and its sensitivity to different methods of treating non-stationarity," Boundary-Layer Meteorology, vol. 159, no. 1, pp. 123-145, 2016.

[15] D. F. Nadeau, E. R. Pardyjak, C. W. Higgins, and M. B. Parlange, "Similarity scaling over a steep alpine slope," Boundary-Layer Meteorology, vol. 147, no. 3, pp. 401-419, 2013.

[16] J. Huang, W. Zhang, J. Zuo et al., “An overview of the semiarid climate and environment research observatory over the loess plateau," Advances in Atmospheric Sciences, vol. 25, no. 6, pp. 906-921, 2008.

[17] Y. Guanghul, L. Zhang, Y. Li, and J.-N. Liang, "Method of acquiring high-quality surface turbulent fluxes over the loess plateau," Chinese Journal of Geophysics (in Chinese), vol. 59, no. 6, pp. 1971-1982, 2016.

[18] J. Liang, Q. Guo, Z. Zhang, M. Zhang, P. Tian, and L. Zhang, "Influence of complex terrain on near-surface turbulence structures over loess plateau," Atmosphere, vol. 11, no. 9, 2020.

[19] J. Liang, L. Zhang, X. Cao, J. Wen, J. Wang, and G. Wang, "Energy balance in the semiarid area of the loess plateau, China," Journal of Geophysical Research: Atmospheres, vol. 122, no. 4, pp. 2155-2168, 2017.

[20] J. Liang, L. Zhang, Y. Wang et al., "Turbulence regimes and the validity of similarity theory in the stable boundary layer over complex terrain of the loess plateau, China," Journal of Geophysical Research: Atmospheres, vol. 119, no. 10, pp. 6009-6021, 2014.

[21] H. I. Reuter, A. Nelson, and A. Jarvis, "An evaluation of voidfilling interpolation methods for SRTM data," International Journal of Geographical Information Science, vol. 21, no. 9, pp. 983-1008, 2007.

[22] D. Vickers and L. Mahrt, "Quality control and flux sampling problems for tower and aircraft data," Journal of Atmospheric and Oceanic Technology, vol. 14, no. 3, pp. 512-526, 1997.

[23] M. Aubinet, T. Vesala, and D. Papale, Eddy Covariance: A Practical Guide to Measurement and Data Analysis, Springer Science \& Business Media, Berlin, Germany, 2012.

[24] P. Schotanus, F. T. M. Nieuwstadt, and H. A. R. De Bruin, "Temperature measurement with a sonic anemometer and its application to heat and moisture fluxes," Boundary-Layer Meteorology, vol. 26, no. 1, pp. 81-93, 1983.

[25] E. K. Webb, G. I. Pearman, and R. Leuning, "Correction of flux measurements for density effects due to heat and water vapour transfer," Quarterly Journal of the Royal Meteorological Society, vol. 106, no. 447, pp. 85-100, 1980.

[26] D. O. Lee, "The influence of atmospheric stability and the urban heat island on urban-rural wind speed differences," Atmospheric Environment (1967), vol. 13, no. 8, pp. 11751180, 1979.

[27] A. Sathe, J. Mann, T. Barlas, W. A. A. M. Bierbooms, and G. J. W. Van Bussel, "Influence of atmospheric stability on wind turbine loads," Wind Energy, vol. 16, no. 7, pp. 1013-1032, 2013.

[28] W. C. Radünz, Y. Sakagami, R. Haas et al., "The variability of wind resources in complex terrain and its relationship with atmospheric stability," Energy Conversion and Management, vol. 222, Article ID 113249, 2020.

[29] A. M. Obukhov, "Turbulence in an atmosphere with a nonuniform temperature," Boundary-Layer Meteorology, vol. 2, no. 1, pp. 7-29, 1971.

[30] A. S. Monin and A. M. Obukhov, "Basic laws of turbulent mixing in the atmospheric surface layer," Trudy Geofiz, Instituta Akademii Nauk, SSSR (Proceedings of Geophysics Institute, National Academy of Science, SSSR), vol. 24, no. 151, pp. 163-187, 1954.

[31] R. B. Stull, An Introduction to Boundary Layer Meteorology, Springer Science \& Business Media, Berlin, Germany, 1988.

[32] H. A. Panofsky, H. Tennekes, D. H. Lenschow, and J. C. Wyngaard, "The characteristics of turbulent velocity components in the surface layer under convective conditions," Boundary-Layer Meteorology, vol. 11, no. 3, pp. 355-361, 1977.

[33] M. L. Wesely, "Use of variance techniques to measure dry airsurface exchange rates," Boundary-Layer Meteorology, vol. 44, no. 1, pp. 13-31, 1988.

[34] J. E. Tillman, "The indirect determination of stability, heat and momentum fluxes in the atmospheric boundary layer from simple scalar variables during dry unstable conditions," Journal of Applied Meteorology, vol. 11, no. 5, pp. 783-792, 1972.

[35] H. A. Panofsky and J. A. Dutton, Atmospheric Turbulence: Models and Methods for Engineering Applications, PrenticeHall, Hoboken, NJ, USA, 1984.

[36] C. Yagüe, S. Viana, G. Maqueda, and J. M. Redondo, "Influence of stability on the flux-profile relationships for wind speed, $\Phi_{m}$, and temperature, $\Phi_{h}$, for the stable atmospheric boundary layer," Nonlinear Processes in Geophysics, vol. 13, no. 2, pp. 185-203, 2006.

[37] C. L. Klipp and L. Mahrt, "Flux-gradient relationship, selfcorrelation and intermittency in the stable boundary layer," Quarterly Journal of the Royal Meteorological Society, vol. 130, no. 601, pp. 2087-2103, 2004.

[38] A. A. Grachev, E. L. Andreas, C. W. Fairall, P. S. Guest, and P. O. G. Persson, "SHEBA flux-profile relationships in the stable atmospheric boundary layer," Boundary-Layer Meteorology, vol. 124, no. 3, pp. 315-333, 2007.

[39] A. A. Grachev, C. W. Fairall, P. O. G. Persson, E. L. Andreas, and P. S. Guest, "Stable boundary-layer scaling regimes: the sheba data," Boundary-Layer Meteorology, vol. 116, no. 2, pp. 201-235, 2005.

[40] E. Kellner and F. Meteorology, "Surface energy fluxes and control of evapotranspiration from a Swedish sphagnum mire," Agricultural and Forest Meteorology, vol. 110, no. 2, pp. 101-123, 2001.

[41] C.-H. Moeng and J. C. Wyngaard, "Evaluation of turbulent transport and dissipation closures in second-order modeling," Journal of the Atmospheric Sciences, vol. 46, no. 14, pp. 2311-2330, 1988. 